\title{
Working
}

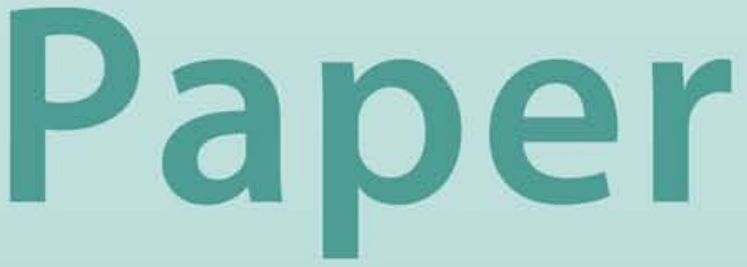


Transition and Regional Inequality in Russia: Reorganization or Procrastination?

Irina Dolinskaya 


\title{
IMF Working Paper
}

IMF Institute

\section{Transition and Regional Inequality in Russia: Reorganization or Procrastination?}

\author{
Prepared by Irina Dolinskaya ${ }^{1}$
}

Authorized for distribution by Eric V. Clifton

October 2002

\begin{tabular}{l} 
Abstract \\
\begin{tabular}{|l|} 
The views expressed in this Working Paper are those of the author(s) and do not necessarily \\
represent those of the IMF or IMF policy. Working Papers describe research in progress by the \\
author(s) and are published to elicit comments and to further debate.
\end{tabular} \\
\hline
\end{tabular}

This paper analyzes the evolution of interregional income inequality during transition in Russia. The transition matrix approach reveals that between 1991 and 1997 income mobility tended toward a highly uneven long-term distribution with the majority of regions at low income levels and a minority of higher-income regions, in sharp contrast to pretransition times. The ordered logit analysis suggests that the more successful regions prospered on account of their natural resources, while continuing to resist economic reorganization by supporting traditional enterprises. The less-successful regions appeared trapped at low income levels due to uncompetitive industries and lack of resources needed for restructuring.

JEL Classification Numbers: O4; P2; R1

Keywords: Growth; transition; inequality

Author's E-Mail Address: idolinskaya@imf.org

${ }^{1}$ The author is grateful to Andrew Feltenstein, Joshua Greene, Vladimir Klyuev, Gene Leon, Eswar Prasad, Paul Seabright, Sunil Sharma, Nikola Spatafora, Emil Stavrev, and Shang-Jin Wei for valuable comments; to Lev Freinkman, Olga Panova, and Plamen Yossifov for help in obtaining data; and to Willem Buiter for general guidance. 


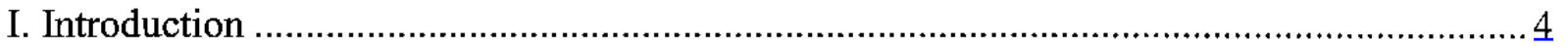

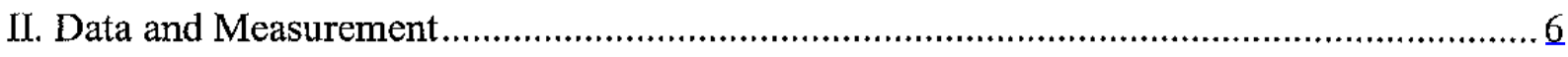

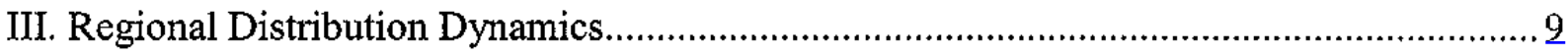

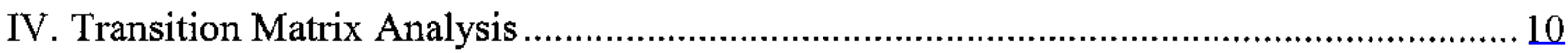

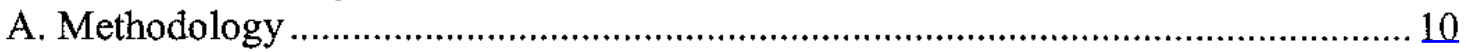

B. Distribution Dynamics Pre- and Post-Reform ………....................................... 13

C. Distribution Dynamics During Transition............................................................ 16

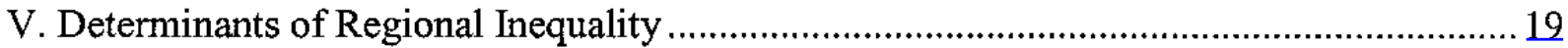

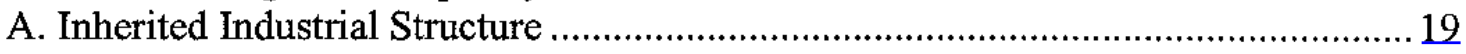

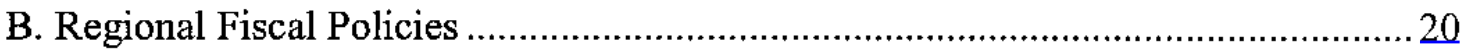

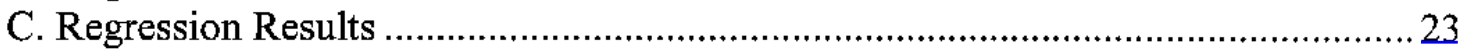

VI. Conclusion

Tables

1. Dynamics of the Regional Income Distribution in Russia..................................................14

2. Evaluation of Model Fit for the Regional Distribution During Transition........................... 17

3. Comparative Dynamics of the Regional Income Distribution During Transition ................ 18

4. Regional Industrial Structure and Income Mobility Groups, 1991-97...........................21

5. Regional Fiscal Position and Income Mobility Groups, 1991-97 ……..............................2

6. Determinants of Regional Income Mobility: Ordered Logit Estimation ...............................26

Figures

1. Per Capita GDP and Real Money Income in 1995-97 (Relative to Mean) ........................... 8

2. Regional Income Distribution in 1995-97: Real Money Income versus GDP....................... 8

3. Evolution of Mean Regional Income Plus/Minus One Standard Deviation ............................ 9

4. Pretransition Evolution of Regional Income Distribution ................................................. 1

5. Transition Evolution of Regional Income Distribution .................................................... 11

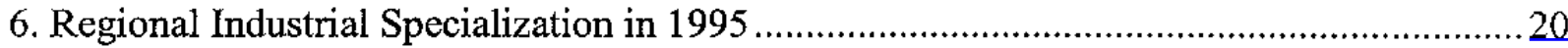

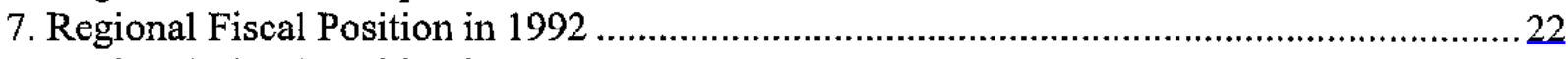

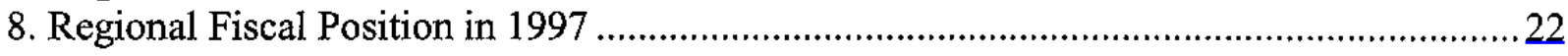

Appendix

1. Transition Evolution of the Regional Income Distribution ............................................28

2. Regional Income Mobility from 1991 (Rows) to 1997 (Columns) ....................................29

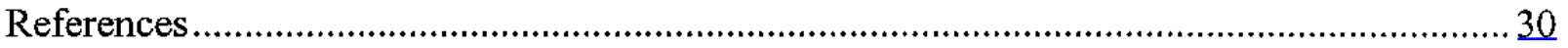




\section{INTRODUCTION}

It is well documented that transition from central planning to a market economy tends to cause an increase in income inequality. While the magnitude of this increase varies across transition economies, it appears particularly large in Russia and other countries of the former Soviet Union. ${ }^{2}$ This is a cause for concern, since recent studies suggest that inequality has a negative effect on economic growth in low-income countries. ${ }^{3}$ It may be a result of imperfect credit markets that limit investment opportunities for poorer households, distortionary redistribution policies or wasteful lobbying by interest groups, or social instability that promotes disruptive activities. Since transition countries form a part of the low-income group, higher inequality is likely to retard their economic recovery.

The observed increase in inequality across transition economies is not entirely surprising. The demise of central planning and its equalization mechanisms could quite naturally lead to a rise in income disparities. Indeed, wage and price liberalization may cause shifts in relative prices that result in a redistribution of income across different economic sectors. The consequent emergence of unemployment and high inflation can further contribute to the redistribution. Privatization of state enterprises and emergence of new private firms may increase earnings dispersion and produce new sources of income for some population groups. At the same time, the equalization impact of changes in the tax system and the structure of public expenditure may differ across countries depending on the direction of government policies. ${ }^{4}$

The observed differences in the dynamics of inequality among transition countries are indeed more perplexing. In particular, a much larger income dispersion in Russia and other countries of the former Soviet Union demands explanation. This difference may be a consequence of the variation in economic policies and their implementation, as well as certain country-specific factors. This paper focuses on a particular dimension of income

${ }^{2}$ Between 1989 and 1995 the Gini coefficient increased from 0.26 to 0.36 in Poland, from 0.22 to 0.32 in Bulgaria, and from 0.22 to 0.48 in Russia (Milanovic, 1999, Aghion and Commander, 1999). Recent studies of the Czech and Slovak Republics (Garner and Terrel, 1998) and Poland (Keane and Prasad, 2000) suggest a more modest increase in income inequality. However, these studies find a substantial rise in wage inequality that was mitigated by social transfers in these countries.

${ }^{3}$ See Barro (2000).

${ }^{4}$ Indeed, while the evidence presented by Garner and Terrel (1998) for the Czech and Slovak Republics and by Keane and Prasad (2000) for Poland shows that government transfers dampened the increase in income inequality, Commander and Lee (1998) suggest that such transfers may in fact have exacerbated the upsurge of inequality in Russia. 
dispersion that tends to be overlooked in most studies of inequality in transition economies. Specifically, the regional component of inequality is important in a number of transition countries, and first and foremost in Russia which has a complex federal structure. Indeed, there is convincing evidence that region-specific factors became progressively more important over the years of reform in accounting for overall income inequality. Thus, Commander and others (1999) report that interregional inequality in Russia accounted for 75 percent of the total increase between 1992 and 1996 and its contribution rose sharply throughout this period. ${ }^{5}$

This paper looks closely at the pattern of evolution of the interregional distribution of income and explores possible determinants of the variation in regional economic performance during transition. Russia presents an unrivalled subject for such a study, having by far the most diverse subnational structure among all transition economies of Eastern Europe and the former Soviet Union. Regional decentralization is one of the principal systemic changes that occurred early in Russia's transition process and allowed regions considerable independence in adapting their economies to new challenges and pursuing relevant economic policies. A number of authors recently explored the regional aspect of the Russian transition (this literature is well represented in a collection of articles in Hanson and Bradshaw, 2000), but a systematic study of regional divergence is not yet available.

It is commonly argued that the principal reason for the observed rise in interregional inequality is industrial specialization. Industry was traditionally the dominant sector of the Russian economy and it largely remains so, even though the share of services has increased during the transition period. ${ }^{6}$ The majority of Russian regions are highly industrialized, but in a rather specialized manner: most regions concentrate on one or two industrial branches, while the other branches are only marginally developed. This specialization is, for the most part, a result of different resource endowments of the regions, exacerbated by central planning that promoted regional dependence. ${ }^{7}$ Such specialization did not have diverging effects when Russia was a centrally planned

${ }^{5}$ Commander and others (1999) use data from the Russian Longitudinal Monitoring Survey and calculate a decomposition of the Theil inequality index by various population categories including the occupational and educational status of the household head, household size, and regional location. The between-group component of inequality for the regional category turns out to be the single dominant factor in overall inequality.

${ }^{6}$ Industry accounted for about 40 percent of GDP in 1991, almost exactly as much as the service sector. The share of services increased to nearly 60 percent of GDP by 1997 , while the share of industry fell to around 30 percent. These figures are taken from the national accounts as reported by Goskomstat and thus represent mostly large and medium-sized enterprises.

${ }^{7}$ For example, in Tyumen almost 80 percent of the total industrial output comes from the fuel industry (namely, oil and gas), in Lipetsk more than 60 percent of output comes from ferrous metallurgy, in Yakutia nonferrous metallurgy accounts for almost 60 percent. 
economy, but began to matter following decentralization and liberalization of foreign trade. Regions endowed with natural resources and specialized in raw materials could take advantage of newly liberalized export markets. In contrast, regions specialized in production of machinery, including defense, and consumer goods found their outputs uncompetitive in the face of foreign alternatives.

Another frequently cited factor behind inter-regional inequality in Russia is a failure of fiscal federalism that, rather than smoothing disparities among regions, actually reinforced them in a chaotic fiscal liberalization. Russia is a large multi-tier federation, ${ }^{8}$ where fiscal decentralization was accomplished quickly during the first few years of transition, but happened largely in a "trial and error" fashion. Within the consolidated budget, the role of the federal budget declined substantially over the transition period, while that of regional and local budgets increased, with a substantial part of the total expenditures switching from the federal level to regions and localities. ${ }^{9}$ The newly acquired fiscal freedom of regions coupled with constantly changing legislation governing their relations with the federal budget and the degree of independence in designing regional public policies may have exacerbated inter-regional differences in economic performance. The wealthier regions could afford to direct more funds to support their relatively lucrative enterprises, while the poorer regions lacked resources to help their ailing economies. ${ }^{10}$ At the same time, federal transfers to regions increased, ${ }^{11}$ but their impact was dubious as their distribution was non-transparent and subject to bargaining. The allocation procedure did little to provide incentives for improving fiscal

${ }^{8}$ The Russian Federation comprises the federal government, 89 regional governments, 1,868 district governments and 650 city governments under regional jurisdiction, and a multitude of governments under district jurisdiction (437 cities, 2,022 townships, and 24,307 villages) (Freinkman, Treisman, and Titov, 1999).

${ }^{9}$ The share of federal expenditures in GDP dropped by 20 percentage points between 1992 and 1997, while the share of regional and local expenditures in GDP increased by 5 percentage points over this period and by 1997 caught up with the federal level of about 20 percent of GDP (Freinkman and Yossifov, 1999).

${ }^{10}$ While federal budgetary subsidies (included in the so-called "national economy expenditure") dropped from over 20 percent of GDP in 1992 to below 2 percent of GDP in 1997, regional and local budgets increased their national economy spending from 5 to nearly 7 percent of GDP during this period. Throughout the transition period, regional and local budgets allocated more than 30 percent of their spending to the national economy item, which consists mainly of subsidies to large local industrial enterprises and former state farms, as well as housing subsidies.

${ }^{11}$ Federal transfers to regions increased significantly over the transition period from 1.7 percent of GDP in 1992 to 2.5 percent of GDP in 1997 (Freinkman and Yossifov, 1999). 
discipline and economic efficiency and its effectiveness in regional equalization varied considerably over the transition period. ${ }^{12}$

This paper analyzes the pattern of regional divergence in Russia using the transition matrix approach that was pioneered by Quah (1993). Unlike conventional regression methods, this approach describes economic performance of regions relative to each other by studying how the whole income distribution evolves over time. It therefore allows for a more flexible relationship between income levels and growth rates than the standard convergence approach. In order to assess the potential determinants of regional divergence, the resulting income mobility pattern is related to variables that reflect inherited industrial structure and regional fiscal position, using the ordered logit technique. The study is based on an extensive dataset covering 89 regions comprising the Russian Federation during the period from 1991 to $1997 .^{13}$

The paper is organized as follows: Section II describes the data used, Section III reviews the dynamics of the income distribution across Russian regions, Section IV analyzes the evolution of the distribution using the transition matrix methodology, Section V looks at possible determinants of regional income mobility, and finally Section VI concludes.

\section{Data And Measurement}

The Russian Federation comprises 89 different regions, of which 78 are distinct and 11 are contained within borders of some of them. The distinct regions are 21 respublikas (ethnic republics), 6 krais (territories), 49 oblasts (provinces), and 2 metropolitan cities (Moscow and St. Petersburg). ${ }^{14}$ The data used in this study come mostly from statistical yearbooks published by the State Committee for Statistics of the

${ }^{12}$ Freinkman and Haney (1997) found that the variation in the after-transfer regional budget revenues did not diminish relative to the pretransfer revenues in the period from 1992 to 1995. Subsequently, Freinkman, Treisman, and Titov (1999) suggested that the variation did go down during the period from 1995 to 1997.

${ }^{13}$ In addition, income data from 1970 to 1990 are used to compare distribution dynamics during transition with that in the preceding period.

${ }^{14}$ Since income data for Chechnya and Ingushetia are not available for most of the period under consideration, these regions are excluded from the sample. Also, since there are no pretransition income data for Adigea, Karachaevo-Cherkessia, Gornii Altai, and Khakasia, they are excluded from the analysis of the pre-transition period. Some krais and oblasts contain within their borders ethnic autonomous okrugs or oblasts (AOs), but most of the data used here do not cover AOs separately, and therefore in this sample these areas are treated as parts of their host regions. In addition, the metropolitan cities (Moscow and St. Petersburg) were excluded from the sample, since their income dynamics is likely to be driven by different factors (such as information advantages and strong scale economies). 
Russian Federation (Goskomstat). ${ }^{15}$ The data covers selected prereform years (1970, $1980,1990)$ and the transition period from 1991 to 1997.

Per capita money income across regions is used as the indicator of living standards and economic performance, since GDP data by region are only available after 1994. Nominal income accounting includes wages, pensions, stipends, other social transfers, revenues from sales of private agricultural produce, interest, dividends, income from entrepreneurial activities, insurance reimbursements, loans, income from sales of foreign currency and some other kinds of income. Real per capita income by region is obtained by deflating the nominal income by regional CPIs in every year from 1992 to $1997 .{ }^{16}$ This adjustment is important in view of the fact that inflation was high and variable across regions, particularly from 1992 to 1995 . Since 1995 both overall inflation and the variability across regions declined substantially, following the completion of price liberalization across regions and the introduction of the exchange rate band. For earlier years there exists no suitable deflator and thus it is assumed that inflation and cross-regional variation in prices were absent before the price liberalization of January 1992. This assumption is not as strong as it may seem, since price variation had been severely restricted by price controls before the reform.

While it would be preferable to use per capita GDP in the analysis of regional distribution dynamics, it turns out that real money income is closely correlated with regional GDP in the years when both series are available (the correlation coefficient is over 0.9 for each year during 1995-97). Figure 1 shows graphically a strong, close to identical relationship between relative per capita income and GDP (averages over 1995-97). Figure 2 confirms that distributions of relative per capita income and GDP (averages over 1995-97) are clearly very similar in shape. In fact, the GDP distribution across regions appears to be somewhat more unequal with thicker tails and a lower peak than that of income. Note that the metropolitan cities (Moscow and St. Petersburg) were excluded from the sample, as their real per capita income substantially exceeds their GDP per capita. Indeed, Moscow particularly is an outlier with respect to the income-GDP relationship: its real per capita income was over 4.5 times the regional mean, while its GDP per capita was just about 2.5 times the regional mean (in the period from 1995 to 1997). However, the resource rich Tyumen oblast (the right-most region in Figure 1) was retained in the sample, since its income and GDP per capita are close, even though both are on average more that 4 times the sample mean (in the period from 1995 to 1997$).^{17}$

\footnotetext{
${ }^{15}$ Regional fiscal indicators are from Freinkman and Yossifov (1999).

16 The CPI inflation is measured as annual average for 1992-95 and end-year for 1996-97.
}

${ }^{17}$ Tyumen's performance, even if somewhat extreme, illustrates important driving forces of regional divergence, while empirical results are sufficiently robust to its exclusion from the sample, as will become apparent below. 


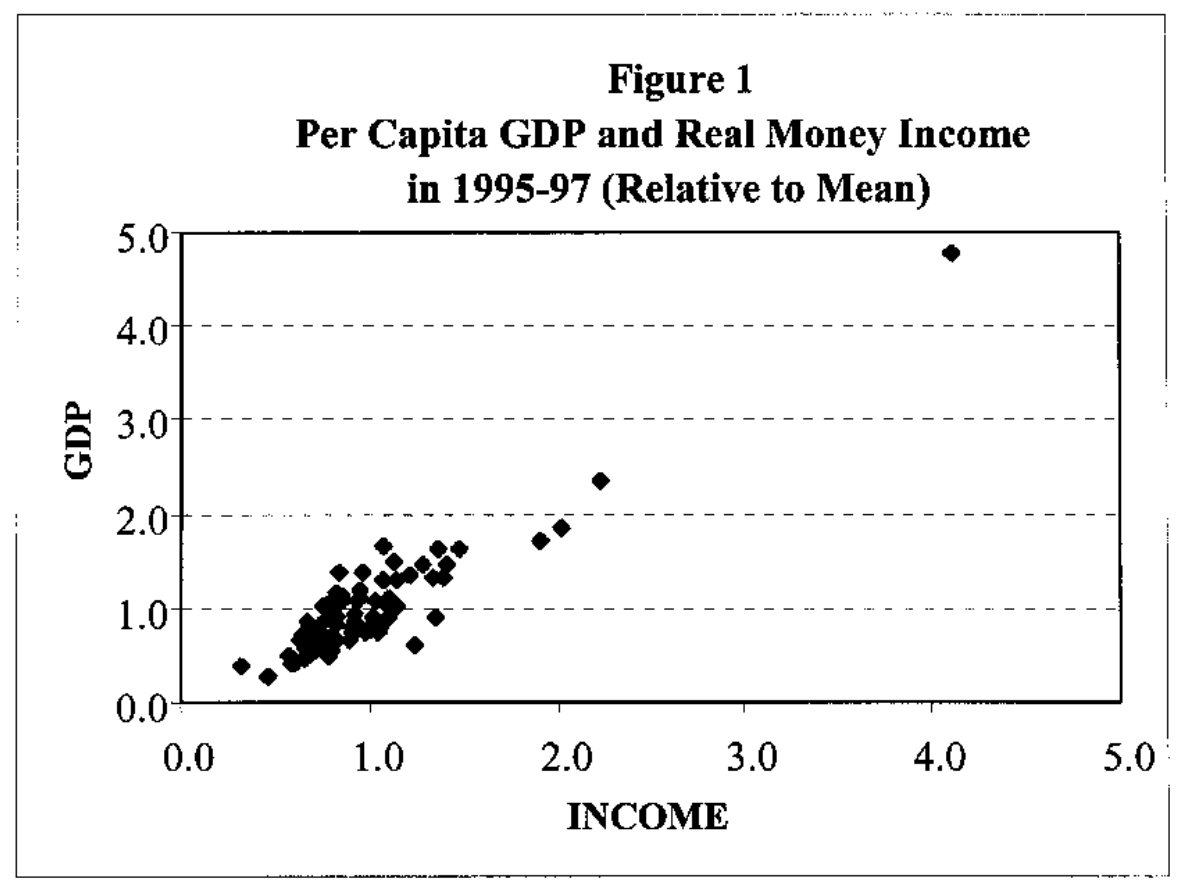

Source: Goskomstat; Author's calculations.

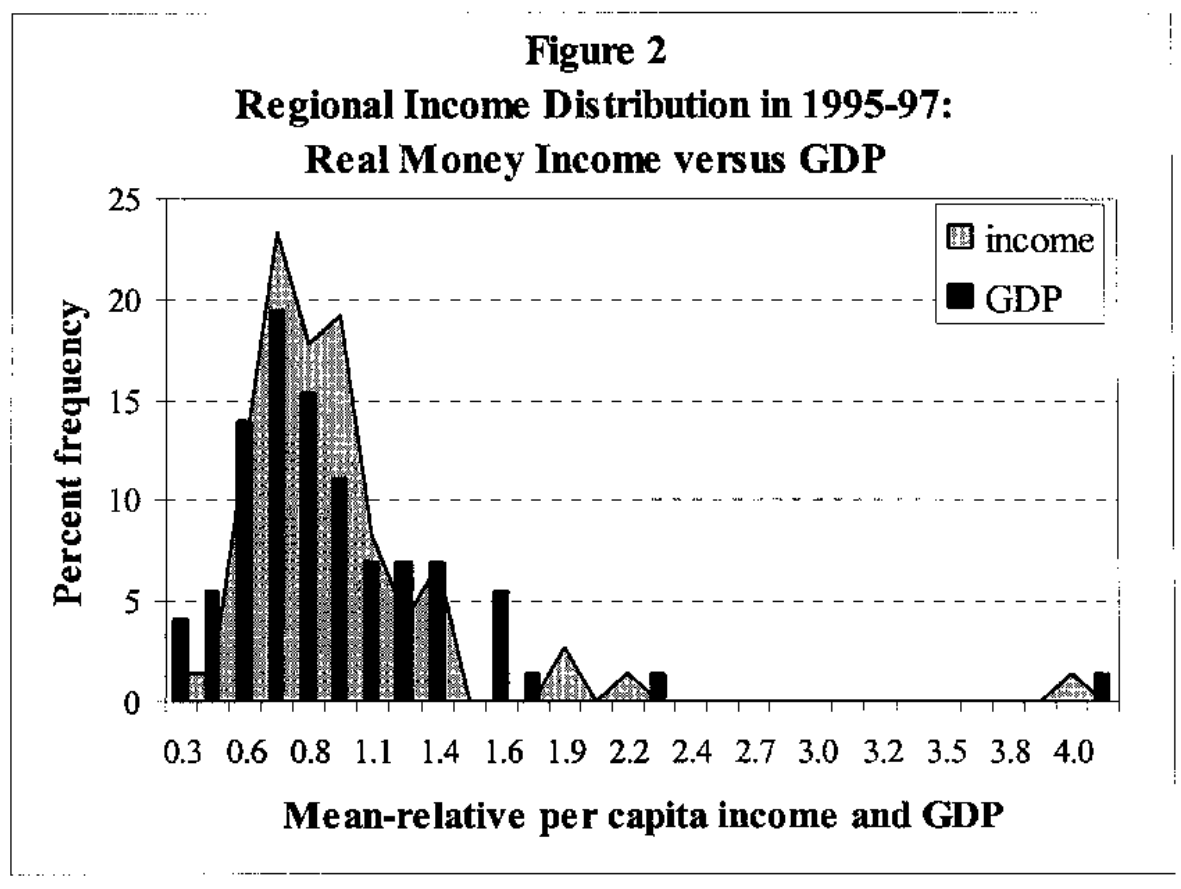

Source: Goskomstat; Author's calculations.

While Goskomstat data contain the most comprehensive set of regional economic indicators, these data are problematic in a number of respects and therefore should be treated with caution. There are comparability problems originating from the rapidly changing economic environment and structural shifts associated with economic transformation. A notorious problem is misreporting: in the socialist time-for 
ideological reasons, and in the transition period - to avoid taxes (both at the enterprise and individual levels). Thus, personal income data suffer from overreporting due to poor account of payment arrears and underreporting due to tax evasion. It is especially difficult to assess the real value of income and wealth: while prior to transition their estimation was troublesome due to widespread scarcities, rationing, and in-kind remunerations and benefits, during transition the problem was compounded by changes in the quality of goods and services and introduction of new types of products. Besides, rapid growth of the informal sector of the economy is poorly accounted for, which leads to biases in reported aggregates. However, cross-regional comparisons may be better justified, assuming the direction of the biases is the same across regions.

\section{REgional Distribution DYNAMics}

Figure 3 shows how the average regional income evolved over time before and during transition and what happened to income dispersion around the mean. The graph exhibits clearly a pattern of rising income and falling inequality in the prereform period and falling income and rising inequality in the post-reform period, especially in the beginning of the transition process. Indeed, the variation coefficient of regional income (standard deviation relative to mean) dropped by 20 percent over the 1970 s and by a further 13 percent over the 1980 s and increased on average by 15 percent every year since 1991, doubling in value by 1997 (it jumped by over 60 percent in 1992 and then grew at a decreasing rate during most of the period). It is worth noting that the mean annual personal income remained very low in dollar terms throughout the transition period, hitting a low of about $\$ 200$ in 1992 and reaching only just over $\$ 1,500$ by 1997 .

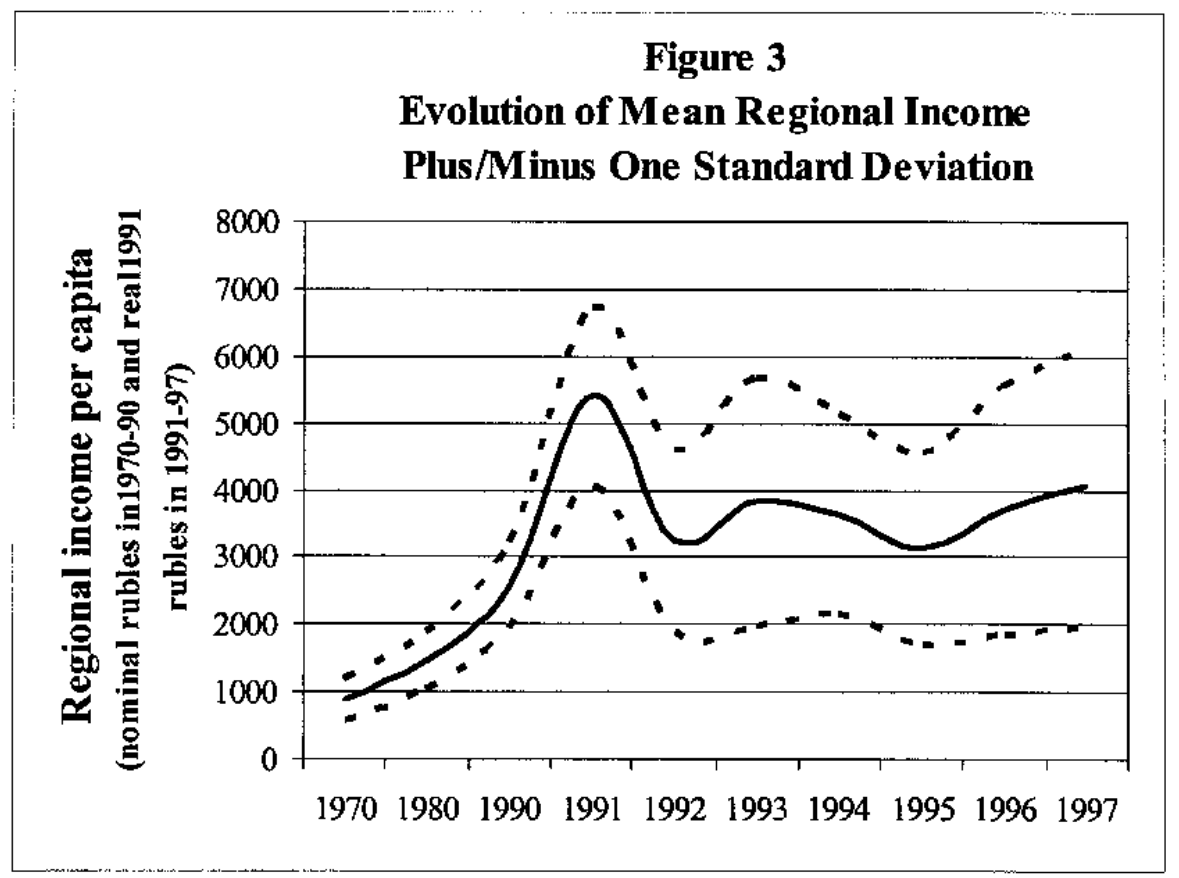

Source: Goskomstat; Author's calculations. 
Figures 4 and 5 provide further evidence of cross-regional convergence prior to the transition and divergence during the reform period. The two figures show frequency distributions across regions of real per capita income before and during the transition period (a more detailed graph for the transition period can be found in Appendix I). Notably, all the distributions are skewed to the left, reflecting that a small number of regions are considerably better off than the rest.

Evidently, during the 1970s and 1980s the distribution narrowed over time, indicating regional convergence, while over the transition period the distributions widened over time, indicating regional divergence. In addition, during the reform period the distribution became progressively more skewed to the left, pointing to the widening gap between the majority of regions and the wealthy minority. It appears from Figure 5 (and Appendix I) that the divergence process occurred primarily during the initial phase of the transition period and regional inequality largely stabilized thereafter at the new level.

It is possible that regional inequality before transition is underestimated by official data. While some of this underestimation is likely to apply equally to all the regions, some could also distort the cross-regional distribution. Underestimation of inequality in the socialist times resulted, among other things, from underrepresentation of certain population groups in population surveys. ${ }^{18}$ Thus, while limiting coverage to fulltime workers and their main jobs in earnings surveys probably affected all regions to the same extent, exclusion of collective farm workers and those working on private agricultural plots (only state farm employees were covered in the agricultural sector) could affect interregional comparisons, since the structure of the agricultural sector varied across regions. In addition, a major share of income (or, more accurately, of the overall living standard) used to come from in-kind compensations channeled through enterprises and local governments. The implications of this for interregional comparisons are not clear, but there are grounds to suppose that in regions with stronger enterprises and local governments a larger share of personal income would come from such non-monetary sources.

\section{Transition Matrix Analysis}

\section{A. Methodology}

The assessment of the dynamics of the regional income distribution is based on the transition matrix methodology that was pioneered by Quah (1993). Since crosssection growth regressions can represent only average behavior, their results may be consistent with diverse patterns of evolution of the income distribution. This is not the case if the transition matrix approach is used, since unlike conventional regression analysis, this method allows one to capture performance of regions relative to each other by studying how the whole distribution evolves over time.

${ }^{18}$ This issue is discussed in detail by Atkinson and Micklewright (1992). 
Figure 4

Pretransition Evolution of Regional Income

Dis tribution

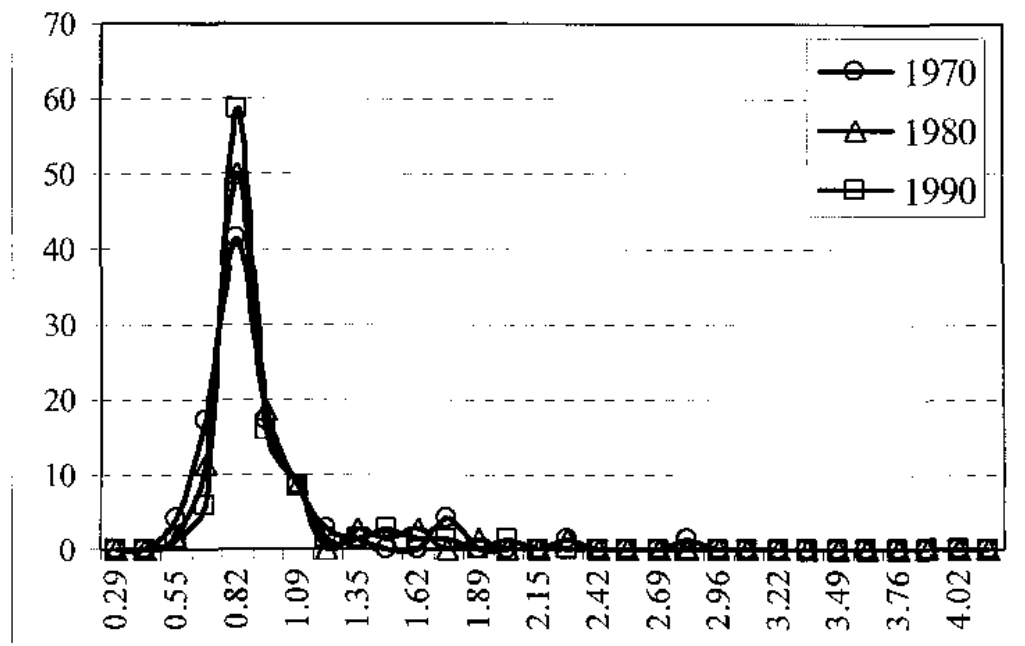

Source: Goskomstat; Author's calculations.

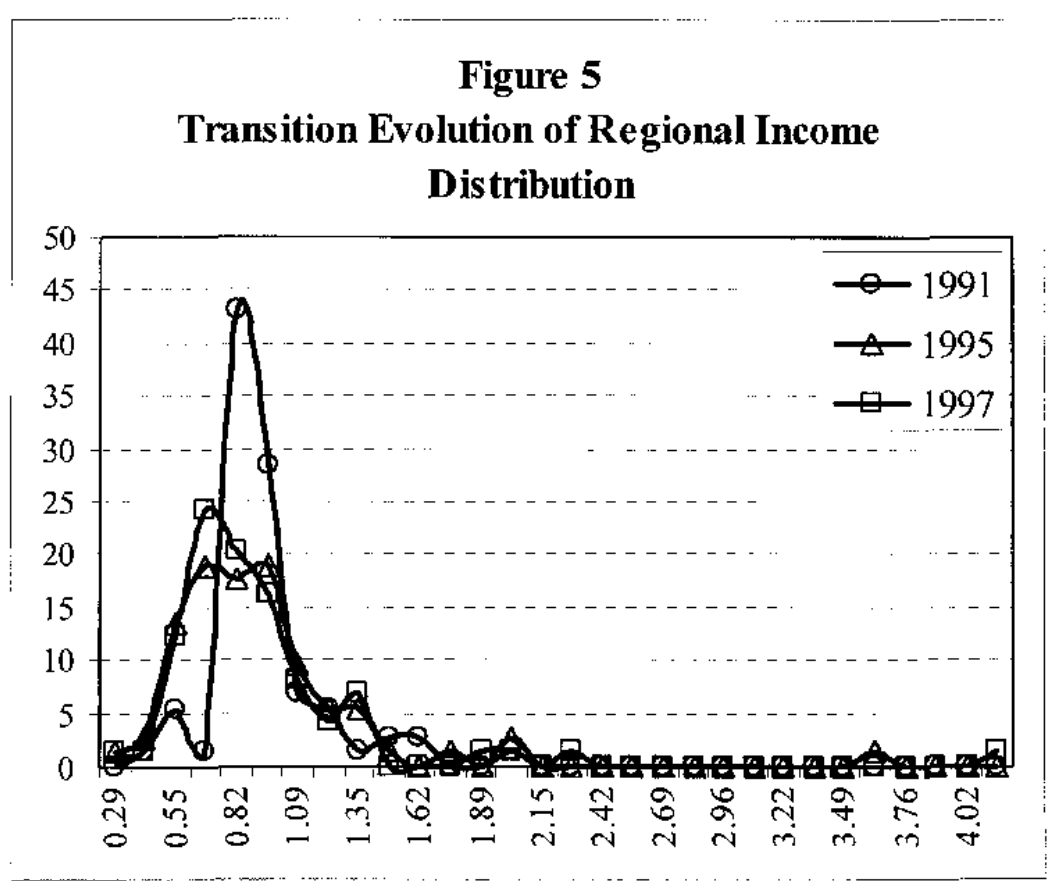

Source: Goskomstat; Author's calculations. 
The simplest empirical model underlying this approach is the one where a (stochastic) difference equation describes the evolution of the sequence of distributions (Quah, 1993). This approach is based on the theory of (first-order) Markov processes, i.e., stochastic processes with the property that given the current realization, future realizations are independent of the past. A (stationary) stochastic process of this kind can be described by a first-order stochastic difference equation (see, for example, Stokey and Lucas, 1989). ${ }^{19}$

Let $F_{t}$ denote the cross-section distribution function at time $t$. The distribution dynamics can be described by the following (stochastic) difference equation:

$$
F_{t+1}=K F_{t}
$$

where the operator $K$ is a stochastic kernel, encoding information on intradistribution dynamics. $K$ maps one distribution into another and tracks where in $F_{t+1}$ points from $F_{t}$ end up. Iterating this equation yields a predictor for future cross-section distributions:

$$
F_{t+s}=(K K \ldots K) F_{t}=K^{s} F_{t} .
$$

Taking this to the limit as $s \rightarrow \infty$ one can characterize the likely long run, or ergodic income distribution. The associated distribution function is invariant, i.e., it is a fixed point of the operator $K$ :

$$
\bar{F}=K \bar{F} \text {. }
$$

Convergence toward equality would manifest in $\left\{F_{t+s}\right\}$ tending toward a degenerate point probability measure, the world polarizing in the long run would manifest in $\left\{F_{t+s}\right\}$ tending toward a two-point, or bimodal measure, and so on. The speed of convergence of the evolving distributions and their cross-sectional mobility properties can be studied from certain characteristics of the kernel $K$.

In practice, in order to estimate $K$ the distributions $F_{t}$ are partitioned into $n$ distinct states so that $F_{t}$ becomes a discrete probability distribution $\lambda_{t}$ and $K$ becomes a Markov chain transition probability matrix $M$ (a Markov chain is a Markov process on a finite state space). Provided every $\lambda_{t}$ is described by a row vector, each element $m_{i j}$ of the

${ }^{19}$ A generalization to higher-order Markov processes can be computationally cumbersome, while robustness of the first-order assumption can be easily checked by redefining the state space to accommodate longer time intervals. Note also that since superiority of the second-order process in the analysis of income distribution has been associated with changes in the direction of income mobility during the sample period (Shorrocks, 1976), an explicit account of such changes may help validate the first-order assumption. 
$n x n$ transition probability matrix $M$ represents the probability of a transition from state $i$ to state $j . M$ is estimated from observed transition frequencies over a certain time period and assumed time-invariant. Under certain fairly unrestrictive regularity conditions (see Stokey and Lucas, 1989) the sequence of transition matrices $\left\{M^{s}\right\}$ converges to a limiting matrix and there exists a unique ergodic distribution for all initial probability distributions. This distribution can be found as a solution to the system of linear equations $\bar{\lambda}=\bar{\lambda} M$ under the condition that the elements of the vector $\bar{\lambda}$ sum to unity.

The choice of discrete income states presents a trade-off between the degree of heterogeneity in income mobility captured by the transition matrix and the precision of estimation of transition probabilities and hence the ergodic distribution. Thus, a potential weakness of the discretization approach is that the resulting ergodic distribution may be sensitive to the choice of states, which led Quah (1997) to suggest the continuous stochastic kernel approach. The present analysis uses the more traditional Markov chain approach, which seems sufficient for the purposes of this paper.

\section{B. Distribution Dynamics Pre- and Post-Reform}

In order to analyze the long term implications of the observed tendencies in regional income distribution, all the regions were grouped into five categories according to real per capita income relative to the mean in the relevant year:

1 - poor (relative income below 0.7 ),

2 - lower middle (relative income above 0.7 but below 0.9 ),

3 - middle (relative income above 0.9 and below 1.1),

4 - upper middle (relative income above 1.1 but below 1.3 ),

5 - rich (relative income above 1.3 ). ${ }^{20}$

The results are presented in Table 1. Cells of the transition matrices show the number of transitions between a pair of states relative to the number of data points in the initial state, i.e., cell $(i, j)$ shows transitions from state $i$ to state $j$ relative to the number of regions initially in state $i$. The cells are arrayed in the increasing order with respect to the relative real per capita income, with the higher left-hand corner displaying transitions from poor to poor and the lower right-hand corner displaying those from rich to rich. The frequency column shows how many regions started their transitions in each of the five states during the whole period and the frequency row shows how many regions ended their transitions in each of the five states. The last row of each matrix contains the resultant ergodic distribution, or the distribution that would prevail in the long run provided that transition dynamics remain unchanged.

${ }^{20}$ Many alternative groupings were tried, both with varying interval bounds and the number of intervals. The findings have been broadly similar across the different groupings. 
Table 1. Dynamics of the Regional Income Distribution in Russia

(a) Prereform distribution dynamics (1970-90, 10-year transitions)

\begin{tabular}{|c|c|ccccc|}
\hline Income group & & $\mathbf{1}$ & $\mathbf{2}$ & $\mathbf{3}$ & $\mathbf{4}$ & $\mathbf{5}$ \\
\hline & Frequency & $\mathbf{2}$ & $\mathbf{4 7}$ & $\mathbf{6 7}$ & $\mathbf{1 1}$ & $\mathbf{1 3}$ \\
\hline $\mathbf{1}$ & $\mathbf{5}$ & $\mathbf{0 . 4 0}$ & 0.60 & 0.00 & 0.00 & 0.00 \\
$\mathbf{2}$ & $\mathbf{4 9}$ & 0.00 & $\mathbf{0 . 6 7}$ & 0.31 & 0.02 & 0.00 \\
$\mathbf{3}$ & $\mathbf{6 2}$ & 0.00 & 0.18 & $\mathbf{0 . 7 7}$ & 0.03 & 0.02 \\
$\mathbf{4}$ & $\mathbf{1 1}$ & 0.00 & 0.00 & 0.36 & $\mathbf{0 . 6 4}$ & 0.00 \\
$\mathbf{5}$ & $\mathbf{1 3}$ & 0.00 & 0.00 & 0.00 & 0.08 & $\mathbf{0 . 9 2}$ \\
\hline \multicolumn{2}{|r}{ Ergodic distribution } & $\mathbf{0 . 0 0}$ & $\mathbf{0 . 2 8}$ & $\mathbf{0 . 5 2}$ & $\mathbf{0 . 0 9}$ & $\mathbf{0 . 1 1}$ \\
\hline
\end{tabular}

(b) Postreform distribution dynamics (1991-97, 1-year transitions) $)^{21}$

\begin{tabular}{|c|c|ccccc|}
\hline Income group & & $\mathbf{1}$ & $\mathbf{2}$ & $\mathbf{3}$ & $\mathbf{4}$ & $\mathbf{5}$ \\
\hline & Frequency & $\mathbf{6 5}$ & $\mathbf{1 5 2}$ & $\mathbf{1 2 6}$ & $\mathbf{4 3}$ & $\mathbf{5 8}$ \\
\hline $\mathbf{1}$ & $\mathbf{5 6}$ & $\mathbf{0 . 8 2}$ & 0.14 & 0.04 & 0.00 & 0.00 \\
$\mathbf{2}$ & $\mathbf{1 4 9}$ & 0.11 & $\mathbf{0 . 7 1}$ & 0.15 & 0.01 & 0.01 \\
$\mathbf{3}$ & $\mathbf{1 4 2}$ & 0.01 & 0.25 & $\mathbf{0 . 6 1}$ & 0.12 & 0.01 \\
$\mathbf{4}$ & $\mathbf{4 3}$ & 0.02 & 0.05 & 0.30 & $\mathbf{0 . 4 4}$ & 0.19 \\
$\mathbf{5}$ & $\mathbf{5 4}$ & 0.00 & 0.02 & 0.02 & 0.09 & $\mathbf{0 . 8 7}$ \\
\hline \multicolumn{2}{r}{ Ergodic distribution } & $\mathbf{0 . 2 2}$ & $\mathbf{0 . 3 2}$ & $\mathbf{0 . 2 2}$ & $\mathbf{0 . 0 8}$ & $\mathbf{0 . 1 6}$ \\
\hline
\end{tabular}

(c) Postreform distribution dynamics (1991-97, 3-year transitions)

\begin{tabular}{|c|c|ccccc|}
\hline Income group & & $\mathbf{1}$ & $\mathbf{2}$ & $\mathbf{3}$ & $\mathbf{4}$ & $\mathbf{5}$ \\
\hline & Frequency & $\mathbf{2 5}$ & $\mathbf{4 2}$ & $\mathbf{4 4}$ & $\mathbf{1 7}$ & $\mathbf{2 0}$ \\
\hline $\mathbf{1}$ & $\mathbf{1 6}$ & $\mathbf{0 . 6 9}$ & 0.12 & 0.06 & 0.12 & 0.00 \\
$\mathbf{2}$ & $\mathbf{3 9}$ & 0.20 & $\mathbf{0 . 4 9}$ & 0.23 & 0.05 & 0.03 \\
$\mathbf{3}$ & $\mathbf{6 0}$ & 0.07 & 0.30 & $\mathbf{0 . 4 8}$ & 0.08 & 0.07 \\
$\mathbf{4}$ & $\mathbf{1 7}$ & 0.12 & 0.12 & 0.23 & $\mathbf{0 . 3 5}$ & 0.18 \\
$\mathbf{5}$ & $\mathbf{1 6}$ & 0.00 & 0.06 & 0.06 & 0.13 & $\mathbf{0 . 7 5}$ \\
\hline \multicolumn{2}{|r}{ Ergodic distribution } & $\mathbf{0 . 2 5}$ & $\mathbf{0 . 2 4}$ & $\mathbf{0 . 2 1}$ & $\mathbf{0 . 1 3}$ & $\mathbf{0 . 1 7}$ \\
\hline
\end{tabular}

${ }^{21}$ A broadly similar estimate of the transition matrix obtains when 1991 - the last year preceding the launch of the reform program--is excluded. The ergodic distribution in this case becomes $(0.21,0.25,0.26,0.11,0.16)$, which is close to the one reported in panel (b). The results also hold when Tyume - by far the richest region in the sample during most of the transition period-is excluded. The transition matrix changes fairly little and the ergodic distribution in this case becomes $(0.15,0.34,0.22,0.10,0.19)$. 
Panel (a) shows the transition matrix for the prereform period estimated from observed regional transitions between the five income states over two ten-year periods. It demonstrates that prior to the start of economic reforms regional per capita income exhibited considerable persistence, meaning that a large fraction of regions belonging to a certain state remained in that state in the following period, as shown by the main diagonal of the matrix. High persistence was reinforced by low cross-sectional mobility: the off-diagonal entries are significantly different from zero only for the first state off the main diagonal of the matrix. Indeed, the persistence was quite remarkable given that the transition matrix was estimated from decade long transitions. The top left diagonal entry is the only one that is below 50 percent, the three middle entries are all above 60 percent, and the bottom right entry exceeds 90 percent.

The probability of remaining in the poor state 1 is below half, while the probability of ever getting into this state from the other states is zero. In contrast, even though the probability of getting into the rich state 5 is basically negligible, the probability of remaining there is over 90 percent. The probability of going down exceeds the probability of going up for states 3,4 , and 5 , while the reverse is true for states 1 and 2 . This suggests that over time poorer regions tend to become richer and richer regions tend to become poorer, i.e., the living standards in different regions converge. The ergodic distribution indeed shows such tendencies: the poor state 1 eventually becomes completely deserted, and over half of the regions tend to the middle state 3 . This shows that before the dismantling of central planning Russian regions tended to converge in per capita income to the mean.

Panels (b) and (c) show regional income mobility over the transition period, based on one-year and three-year transitions, respectively. Kremer, Onatski, and Stock (2001) suggest that using longer transition periods gives more accurate estimates of the transition matrix and hence the ergodic distribution. Indeed, when longer transition periods are considered, the assumption of a first order Markov process is more likely to hold and the noise effect of short term fluctuations in incomes is eliminated. On the other hand, the use of longer transition periods comes at a cost of the decreased sample size.

It is evident from panels (b) and (c) that regional per capita income exhibits lower persistence and higher cross-sectional mobility during the reform period, than during the preceding decades. Indeed, the rise in intra-distribution churning since 1991 appears quite striking, when one compares panel (c) based on three-year transitions to panel (a) based on ten-year transitions. According to panel (c), the probability of staying in any of the three middle states is below $1 / 2$ and off-diagonal entries are nonzero for three states off the main diagonal. The polar states 1 and 5 are the most persistent: over 80 percent of regions that get into either one of these stay for the following year (panel (b)) and around 70 percent stay for the following three years (panel (c)). The probability of going down significantly exceeds the probability of going up for states $3,4,5$ and is only slightly lower than that for state 2 in both panels (b) and (c), suggesting that downward income mobility tends to dominate upward mobility in the post-reform distribution.

Accordingly, over time the weak convergence tendency is overcome by the tendency toward relative impoverishment of the majority of regions. The ergodic 
distributions of both panels (b) and (c) indeed show such tendencies: states 1 and 2 are predicted to attract eventually around half of all regions, while states 4 and 5 are likely to attract just about one-fourth. When based on one-year transitions, state 2 ends up the most populated with 32 percent of all regions, and when based on three-year transitions, states 1 and 2 end up with approximately equal numbers and state 4 gets accordingly more. The differences between these two models are therefore minor, while their difference from the pretransition model is large. In contrast to the pretransition dynamics, regional mobility over the reform period tends to a highly uneven long term distribution with the majority of regions at relatively low income levels and a minority of highincome regions.

The fit of the Markov chain model can be evaluated by comparing the actual long run transition matrix with the estimated stationary model raised to an appropriate power (determined by the length of the time series and the time span of the model). As shown in Table 2, for some income states the one-year model produces a better fit, while for others the three-year model works better. This largely reflects the trade-off between the length of the transition period and the sample size in estimating the Markov matrix. The general difficulty of obtaining a good model fit stems from the shortness of the time series and the uneven mobility pattern, both characteristic of the transition environment. While both models are clearly imprecise, they capture the direction of cross-sectional mobility adequately and therefore both produce ergodic distributions that are very similar to that of the long run matrix shown in panel (a).

\section{Distribution Dynamics During Transition}

The evolution of the regional income distribution during transition shown in Figure 5 above (and in more detail in Appendix I) suggests that divergence occurred primarily in the early part of the period (1991 to 1995) and that the distribution began to stabilize or even tend back toward convergence later on (1995 to 1997). Such dynamics would be consistent with the Kuznets hypothesis, according to which inequality first increases and later decreases during the process of economic development. Indeed, one can view transition as a gradual shift from a less efficient economic system to a more efficient one, with inequality initially rising as a small number of regions embark on economic transformation and later falling as most regions undergo a market-oriented reorganization.

In order to assess the extent of the seeming reversal of the divergence pattern in 1995, transition matrices and ergodic distributions were computed separately for the two subperiods. A comparison of the transition matrices for 1991-95 and 1995-97 shown in Table 3 confirms that regional income mobility was notably more stable over the later subperiod. While the 1991-95 matrix and the associated ergodic distribution are fairly similar to those of Table 1 (panel (b)), the larger main diagonal elements of the 1995-97 matrix indicate more persistence in the distribution, and zero values further off the main diagonal show a marked drop in income churning during this later segment. In fact, the 1995-97 matrix has nonzero elements for only one state off the main diagonal, meaning that the regions only moved to adjacent states during this subperiod. This matrix is 
therefore of the so-called "triple-diagonal" kind, usually observed in similar studies of the world income distribution (Kremer, Onatski, and Stock, 2001).

Table 2. Evaluation of Model Fit for the Regional Distribution During Transition (a) Actual transitions between 1991 and 1997

\begin{tabular}{|c|c|ccccc|}
\hline Income group & & $\mathbf{1}$ & $\mathbf{2}$ & $\mathbf{3}$ & $\mathbf{4}$ & $\mathbf{5}$ \\
\hline $\boldsymbol{I}$ & Frequency & $\mathbf{1 4}$ & $\mathbf{2 1}$ & $\mathbf{2 1}$ & $\boldsymbol{8}$ & $\mathbf{1 0}$ \\
\hline $\mathbf{2}$ & $\mathbf{5}$ & $\mathbf{0 . 4 0}$ & 0.40 & 0.20 & 0.00 & 0.00 \\
$\mathbf{3}$ & $\mathbf{1 8}$ & 0.44 & $\mathbf{0 . 1 7}$ & 0.33 & 0.06 & 0.00 \\
$\mathbf{4}$ & $\mathbf{3 7}$ & 0.08 & 0.38 & $\mathbf{0 . 3 2}$ & 0.14 & 0.08 \\
$\mathbf{5}$ & $\boldsymbol{8}$ & 0.12 & 0.12 & 0.25 & $\mathbf{0 . 1 2}$ & 0.38 \\
$\mathbf{6}$ & $\mathbf{6}$ & 0.00 & 0.17 & 0.00 & 0.17 & $\mathbf{0 . 6 7}$ \\
\hline Ergodic distribution & $\mathbf{0 . 2 5}$ & $\mathbf{0 . 2 7}$ & $\mathbf{0 . 2 4}$ & $\mathbf{0 . 0 8}$ & $\mathbf{0 . 1 5}$ \\
\hline
\end{tabular}

(b) Transition matrix estimated from 1-year transitions to power 6

\begin{tabular}{|c|c|ccccc|}
\hline Income group & & $\mathbf{1}$ & $\mathbf{2}$ & $\mathbf{3}$ & $\mathbf{4}$ & $\mathbf{5}$ \\
\hline & & & & & & \\
\hline $\mathbf{1}$ & & $\mathbf{0 . 4 2}$ & 0.34 & 0.17 & 0.04 & 0.03 \\
$\mathbf{3}$ & & 0.25 & $\mathbf{0 . 3 8}$ & 0.24 & 0.07 & 0.06 \\
$\mathbf{4}$ & & 0.16 & 0.36 & $\mathbf{0 . 2 7}$ & 0.09 & 0.12 \\
$\mathbf{5}$ & & 0.11 & 0.27 & 0.24 & $\mathbf{0 . 1 1}$ & 0.26 \\
& & 0.04 & 0.14 & 0.16 & 0.13 & $\mathbf{0 . 5 3}$ \\
\hline
\end{tabular}

(c) Transition matrix estimated from 3-year transitions to power 2

\begin{tabular}{|c|c|ccccc|}
\hline Income group & & $\mathbf{1}$ & $\mathbf{2}$ & $\mathbf{3}$ & $\mathbf{4}$ & $\mathbf{5}$ \\
\hline & & & & & & \\
\hline $\boldsymbol{I}$ & & $\mathbf{0 . 5 2}$ & 0.18 & 0.13 & 0.14 & 0.03 \\
$\mathbf{3}$ & & 0.26 & $\mathbf{0 . 3 4}$ & 0.25 & 0.09 & 0.06 \\
$\mathbf{4}$ & & 0.15 & 0.31 & $\mathbf{0 . 3 3}$ & 0.10 & 0.10 \\
$\mathbf{5}$ & & 0.16 & 0.20 & 0.24 & $\mathbf{0 . 1 9}$ & 0.21 \\
& & 0.03 & 0.11 & 0.12 & 0.15 & $\mathbf{0 . 5 9}$ \\
\hline
\end{tabular}

A comparison of the ergodic distributions for the two subperiods reveals two major differences. First, the share of regions tending toward the middle income state is 10 percentage points higher for 1995-97 than for 1991-95. Second, the share of regions ending up in the rich state is 14 percentage points lower for 1995-97 than for 1991-95. There is also an important similarity between the two distributions: the concentration of regions at the lower end is a notable feature of both. These findings suggest that in the later part of the transition period the tendency for regional divergence was to some extent reversed, but the tendency for the majority of regions to be stuck at relatively low income levels remained. These observations appear to contradict the Kuznets view and instead suggest that most of the regions fail to catch up and remain trapped in low income states. 
Table 3. Comparative Dynamics of the Regional Income Distribution During Transition (a) Early distribution dynamics (1991--95, 1-year transitions)

\begin{tabular}{|c|c|ccccc|}
\hline Income group & & $\mathbf{1}$ & $\mathbf{2}$ & $\mathbf{3}$ & $\mathbf{4}$ & $\mathbf{5}$ \\
\hline & Frequency & $\mathbf{3 9}$ & $\mathbf{1 0 6}$ & $\mathbf{8 3}$ & $\mathbf{2 9}$ & $\mathbf{3 9}$ \\
\hline $\mathbf{1}$ & $\mathbf{3 0}$ & $\mathbf{0 . 7 7}$ & 0.17 & 0.07 & 0.00 & 0.00 \\
$\mathbf{2}$ & $\mathbf{1 0 3}$ & 0.14 & $\mathbf{0 . 6 6}$ & 0.17 & 0.02 & 0.01 \\
$\mathbf{3}$ & $\mathbf{1 0 1}$ & 0.01 & 0.30 & $\mathbf{0 . 5 5}$ & 0.12 & 0.02 \\
$\mathbf{4}$ & $\mathbf{2 8}$ & 0.04 & 0.07 & 0.21 & $\mathbf{0 . 4 3}$ & 0.25 \\
$\mathbf{5}$ & $\mathbf{3 4}$ & 0.00 & 0.03 & 0.03 & 0.09 & $\mathbf{0 . 8 5}$ \\
\hline \multicolumn{2}{|r|}{ Ergodic distribution } & $\mathbf{0 . 2 0}$ & $\mathbf{0 . 3 2}$ & $\mathbf{0 . 2 1}$ & $\mathbf{0 . 0 8}$ & $\mathbf{0 . 1 9}$ \\
\hline
\end{tabular}

(b) Late distribution dynamics (1995-97, 1-year transitions)

\begin{tabular}{|c|c|c|c|c|c|c|}
\hline Income group & & 1 & 2 & 3 & 4 & 5 \\
\hline & Frequency & 26 & 46 & 43 & 14 & 19 \\
\hline 1 & 26 & 0.88 & 0.12 & 0.00 & 0.00 & 0.00 \\
\hline 2 & 46 & 0.06 & 0.83 & 0.11 & 0.00 & 0.00 \\
\hline 3 & 41 & 0.00 & 0.12 & 0.76 & 0.12 & 0.00 \\
\hline 4 & 15 & 0.00 & 0.00 & 0.47 & 0.47 & 0.07 \\
\hline 5 & 20 & 0.00 & 0.00 & 0.00 & 0.10 & 0.90 \\
\hline \multicolumn{2}{|c|}{ Ergodic distribution } & 0.20 & 0.35 & 0.31 & 0.08 & 0.05 \\
\hline
\end{tabular}

The triple-diagonal form of the 1995-97 transition matrix allows one to perform some formal statistical tests on the shape of the ergodic distribution. Note that after one transition, the probability of being in state $i$ equals the probability of initially being in state $i$ and remaining there plus the probabilities of initially being in an adjacent state $i-1$ or $i+1$ and transiting to state $i$. It is easy to see that in this case ergodic probabilities $\bar{\lambda}_{i}$ are related to transition probabilities $m_{i j}$ in the following simple way:

$$
\frac{\bar{\lambda}_{i}}{\bar{\lambda}_{i+1}}=\frac{m_{i+1, i}}{m_{i, i+1}}
$$

Hence, linear restrictions on ergodic probabilities can be reformulated as linear restrictions on transition probabilities. Kremer, Onatski, and Stock (2001) show that a test of equality of the ergodic distribution to a given distribution is a likelihood ratio test of equality restrictions on multinomial transition probabilities. In other words, the distribution of transitions from each state $i$ can be approximated by the multinomial distribution with the number of trials equal to the number of regions initially in state $i$ and the probabilities equal to the transition probabilities from state $i$ to each of the states from $I$ to $n$. The likelihood ratio test statistic has an asymptotic Chi-squared distribution with degrees of freedom equal to the number of restrictions. 
There is an interesting hypothesis about the ergodic distribution in the second phase of the transition period that is testable using this approach under the triple-diagonal assumption. Specifically, one can test for a structural break between the two subperiods by testing whether the ergodic distribution of 1995-97 equals that of 1991-95, which is $(0.20,0.32,0.21,0.08,0.19)$. This amounts to testing the validity of the following restrictions:

$$
\frac{m_{21}}{m_{12}}=\frac{20}{32}, \frac{m_{32}}{m_{23}}=\frac{32}{21}, \frac{m_{43}}{m_{34}}=\frac{21}{8}, \frac{m_{54}}{m_{45}}=\frac{8}{19} .
$$

The resulting likelihood ratio test statistic is 2.10 , which corresponds to the Chi-squared $\mathrm{P}$-value of 0.28 . Hence, the null hypothesis about the equality of the two ergodic distributions cannot be rejected at standard significance levels. Therefore, even though the data show certain signs of a structural break in 1995, the evidence for such a break is statistically weak.

\section{DETERminants of Regional INEQUALITY}

\section{A. Inherited Industrial Structure}

It is often argued that the high degree of industrial specialization in prereform Russia may have caused a rise in interregional income inequality following decentralization and liberalization of foreign trade. In transition, resource-extracting regions can benefit from exporting primary products and increasing their exposure to the world market, while resource-processing regions may collapse due to lack of competitiveness of their products and lack of domestic demand. Hence, the industrial specialization effect can result in a polarization of regions into a richer extracting cluster and a poorer processing cluster.

Figure 6 shows a scatter plot of regions by shares of extracting and processing industries in their industrial output in 1995. Since this separation is largely determined by regional resource endowments and traditional location of large industrial plants, it is unlikely to change fast, hence the picture in 1995 should be fairly similar to the one at the outset of economic reforms. Extracting industries in this graph include fuel production (oil, gas, coal) and processing industries include various machinery (defense, industrial and other equipment), construction materials and light industry. It is evident that regions are mostly separated into extraction-intensive and processing-intensive clusters.

Table 4 gives a preliminary assessment of the impact of this separation on regional income performance. The table matches the shares of extracting and processing industries to the income transition matrix over the period from 1991 to 1997. This sixyear transition matrix is shown in Appendix II with the cells filled in with the corresponding regions. This matrix effectively divides all the regions into 25 income mobility groups according to their performance in 1997 as compared to 1991. Table 4 shows average shares of extracting and processing industries by these income mobility groups. It is easy to see the general trend in the table: the share of extracting industries rises from left to right and diagonally from top to bottom (panel (a)), while the share of 
processing industries falls accordingly (panel (b)). The two shares are approximately equal in the middle income group $(3,3)$, but as one moves away from this benchmark the differences widen. The share of extraction of the rich group $(5,5)$ is 10 times more than that of the poor group $(1,1)$, while the share of processing is nearly 4 times less.

Similarly, regions in the income cell $(3,5)$ that succeeded in moving from the middle to the rich group are characterized by over 12 times more extracting and about 1.5 times less processing on average than the failing regions in the income cell $(3,1)$. These observations support the idea that inherited economic structure was important in generating interregional income inequality during transition in Russia. Indeed, it appears that over the period from 1991 to 1997 the regions specialized in uncompetitive industries were trapped at low income levels, while the regions rich in natural resources lived off their export revenues.

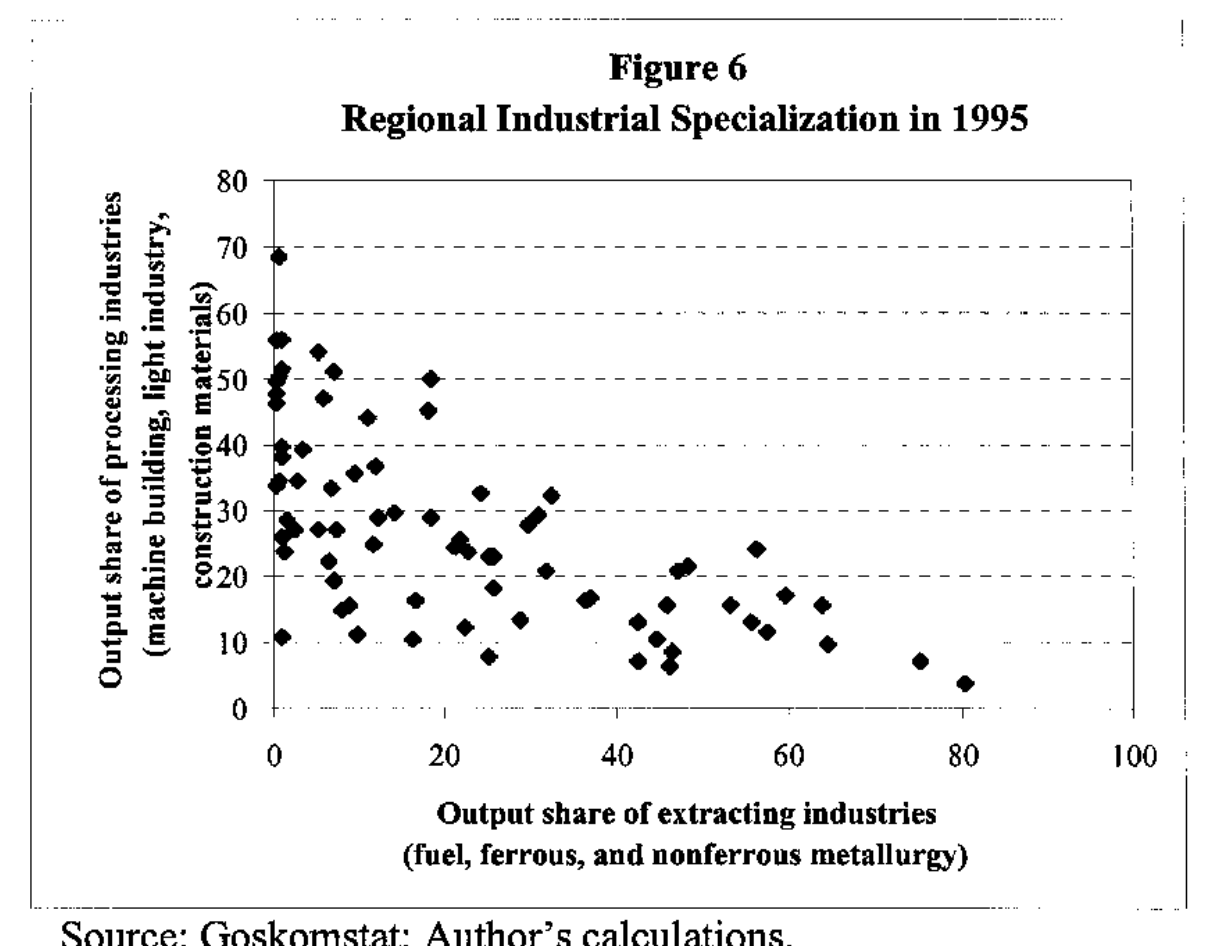

Source: Goskomstat; Author's calculations.

\section{B. Regional Fiscal Policies}

The interregional differences in economic performance may have been exacerbated by the fiscal decentralization that gave regions considerable independence in designing their policies but did not provide adequate incentives for advancement of market-oriented reforms. Conceivably, regions could choose to follow a strategy of extending public support to inefficient enterprises instead of promoting a more efficient private sector. Interregional inequality would increase if the wealthier regions directed more public funds to support their relatively stronger economies, while the poorer regions lacked resources to support their relatively weaker ones. Such fiscal decentralization could have substantial effects if the system of federal transfers failed to moderate inequalities. 
Table 4. Regional Industrial Structure and Income Mobility Groups, 1991-97

(a) Percent share of extracting in regional industrial output, group mean as of 1995

\begin{tabular}{|c|ccccc|}
\hline Income group & $\mathbf{1}$ & $\mathbf{2}$ & $\mathbf{3}$ & $\mathbf{4}$ & $\mathbf{5}$ \\
\hline $\mathbf{1}$ & $\mathbf{5}$ & 8 & 53 & $\ldots$ & $\ldots$ \\
$\mathbf{2}$ & 14 & 2 & 16 & 26 & $\ldots$ \\
$\mathbf{3}$ & 3 & 18 & 22 & 27 & 37 \\
$\mathbf{4}$ & 17 & $\mathbf{8}$ & 19 & 65 & 45 \\
$\mathbf{5}$ & $\ldots$ & 25 & $\ldots$ & 43 & 51 \\
\hline
\end{tabular}

(b) Percent share of processing in regional industrial output, group mean as of 1995

\begin{tabular}{|c|ccccc|}
\hline Income group & $\mathbf{1}$ & $\mathbf{2}$ & $\mathbf{3}$ & $\mathbf{4}$ & $\mathbf{5}$ \\
\hline $\boldsymbol{1}$ & 30 & 34 & 16 & $\ldots$ & $\ldots$ \\
$\mathbf{2}$ & 31 & 36 & 25 & 18 & $\ldots$ \\
$\mathbf{3}$ & 46 & 35 & 25 & 32 & 28 \\
$\mathbf{4}$ & 16 & 15 & 17 & 10 & 14 \\
$\mathbf{5}$ & $\ldots$ & 8 & $\ldots$ & 7 & 7 \\
\hline
\end{tabular}

Figures 7 and 8 show scatter plots of regions by shares of regional and local spending on national economy ${ }^{22}$ and by federal transfers in regional budget expenditure in 1992 and 1997, respectively. It turns out that while the spread of regional subsidization levels remained largely unchanged during the transition period, the spread of federal transfers allocated to regions increased dramatically. At the same time, while there is a clear negative relationship between national economy spending and federal transfers in 1992, it all but disappears by 1997 . These observations suggest that the traditional inclination to subsidize important enterprises remained largely intact at the regional level and that while the federal government increased its involvement with regional budgets, the equalization and/or incentive effect of federal transfers was ambiguous.

Of course, the changing patterns of federal support to regional budgets can be both an outcome and a cause of growing regional inequality. On the one hand, regional incomes at least to some extent have determined the allocation of federal transfers aimed at equalization. On the other hand, regions receiving more federal transfers may have had fewer incentives to improve their policies and hence may have become dependent on the helping hand of the center. These effects are difficult to separate, as they both manifest themselves in poorer regions having more federal support and richer regions having less.

${ }^{22}$ National economy expenditure, according to Russian budgetary classification, includes subsidies to large industrial enterprises and former state farms, as well as housing subsidies, at the federal, regional, or local level. In what follows, the term "national economy" is used to denote such regional subsidy spending. 
themselves in poorer regions having more federal support and richer regions having less. However, if federal transfers were allocated on the basis of bargaining power to more powerful rather than more needy regions, the relationship between regional income and federal support would be reversed.

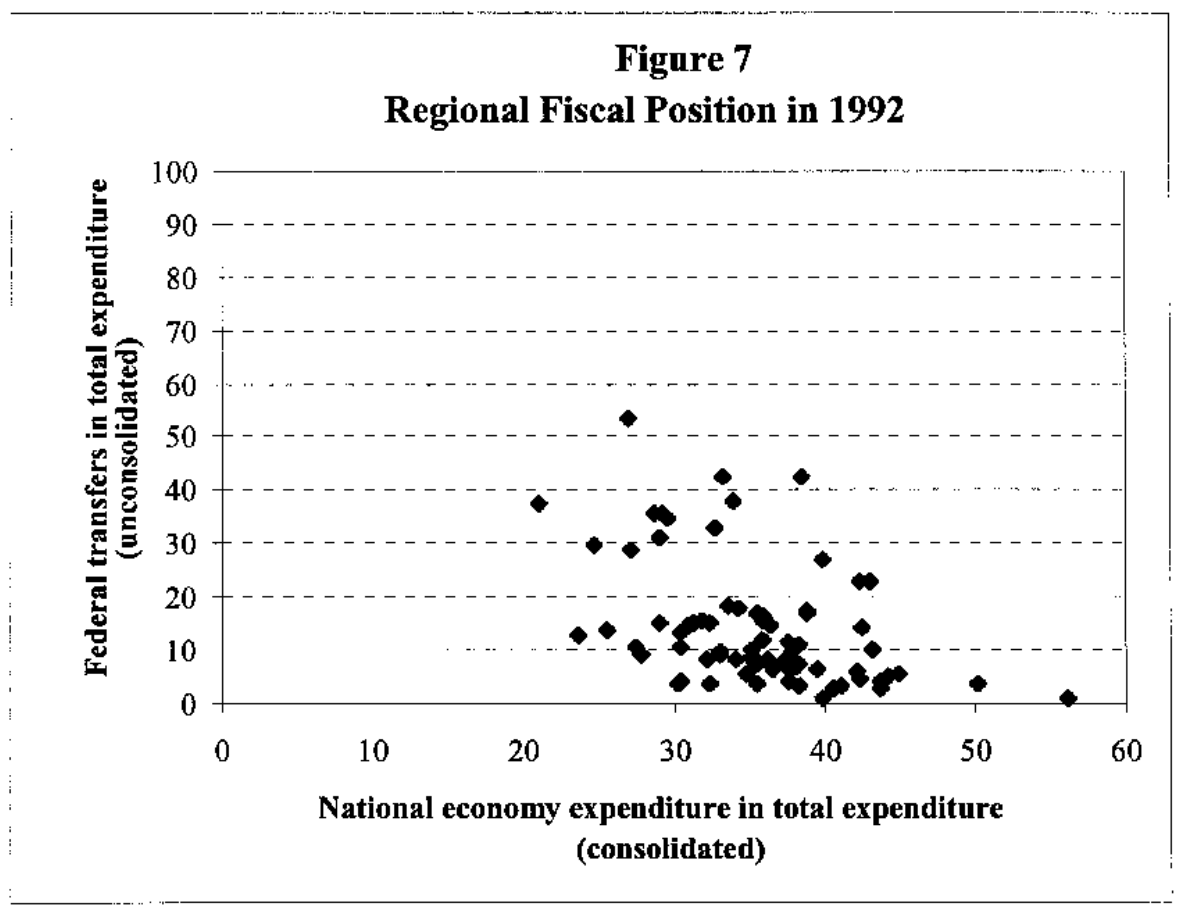

Source: Freinkman and Yossifov (1999); Author's calculations.

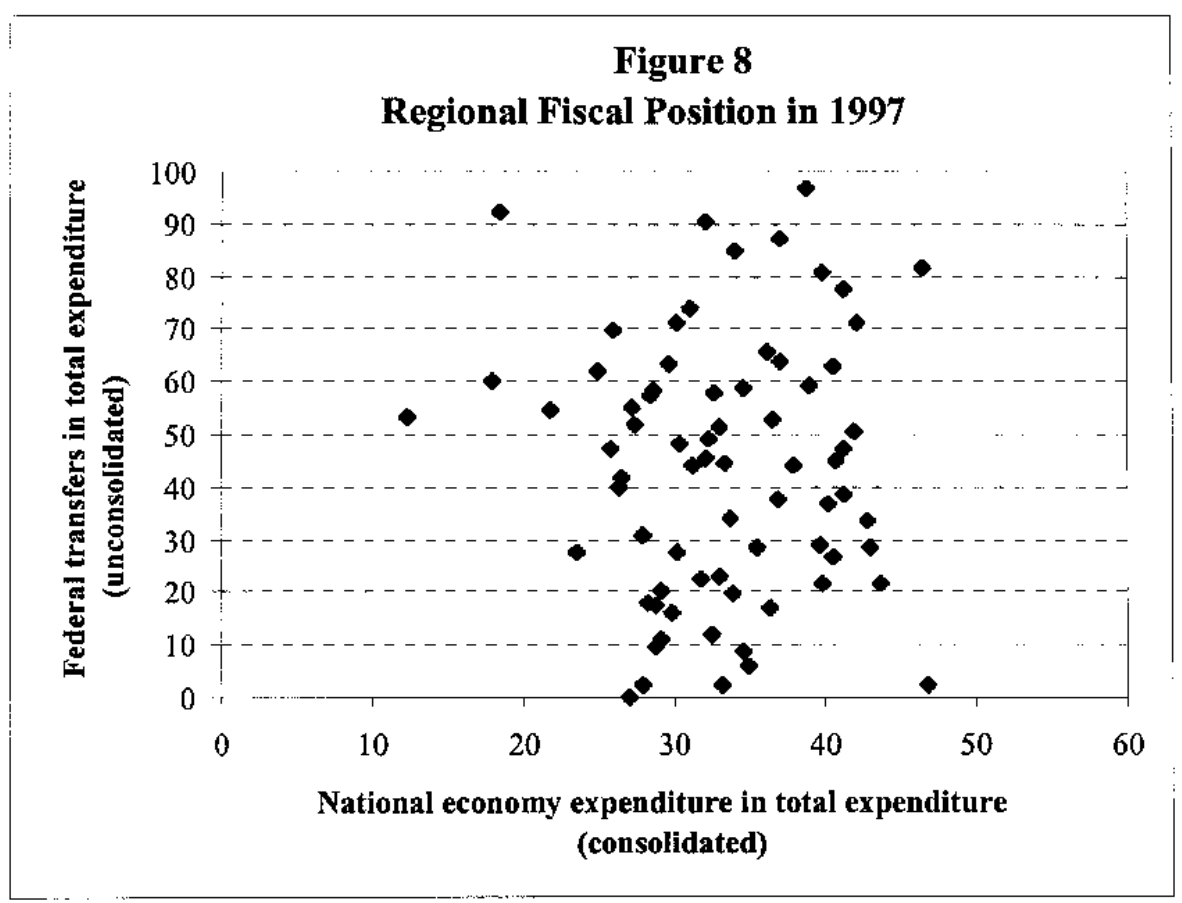

Source: Freinkman and Yossifov (1999); Author's calculations. 
Table 5 gives a preliminary assessment of the relationship between changes in regional fiscal circumstances and income performance. Similarly to Table 4 above, this table matches these changes to the income transition matrix over the period from 1991 to 1997 (see Appendix II). It shows changes in the shares of federal transfers and regional spending on national economy in total regional expenditure between 1992 and 1997 by income mobility groups. Panel (a) shows that increases in federal transfers become smaller from left to right and diagonally from top to bottom of the table, broadly consistent with the equalization principle. Note, however, that even though the rise in transfers was much more pronounced for the low or declining income groups, it was also evident for most of the richer groups that already received significant federal funding. As regards the subsidization indicator (panel (b)), changes in national economy spending tend to be negative in the upper left half of the table and positive in the lower right half. For example, while regions in the weakening group $(3,1)$ cut down on their subsidies by an average of 3 percentage points as compared to the level of 1992, those in the thriving group $(3,5)$ increased their subsidization level by 2 percentage points. These observations support the idea that growing income inequality over the period was exacerbated by regional fiscal subsidies. Federal fiscal policy in the form of transfers to regional budgets, while broadly equalizing, did not mitigate sufficiently the inter-regional disparities.

Table 5. Regional Fiscal Position and Income Mobility Groups, 1991-97

(a) Percent share of federal transfers in regional budget expenditure (unconsolidated), mean change between 1992 and 1997

\begin{tabular}{|c|ccccc|}
\hline Income group & $\mathbf{1}$ & $\mathbf{2}$ & $\mathbf{3}$ & $\mathbf{4}$ & $\mathbf{5}$ \\
\hline $\boldsymbol{1}$ & +66 & +69 & +35 & $\ldots$ & $\ldots$ \\
$\mathbf{2}$ & +38 & +25 & +17 & +13 & $\ldots$ \\
$\mathbf{3}$ & +51 & +27 & +32 & +31 & +14 \\
$\mathbf{4}$ & +43 & +51 & +6 & +14 & -19 \\
$\mathbf{5}$ & $\ldots$ & +52 & $\ldots$ & +66 & +12 \\
\hline
\end{tabular}

(b) Percent share of national economy spending in regional expenditure (consolidated), mean change between 1992 and 1997

\begin{tabular}{|c|ccccc|}
\hline Income group & $\mathbf{1}$ & $\mathbf{2}$ & $\mathbf{3}$ & $\mathbf{4}$ & $\mathbf{5}$ \\
\hline $\boldsymbol{1}$ & +3 & -7 & +0 & $\ldots$ & $\ldots$ \\
$\mathbf{2}$ & -6 & -5 & -7 & -6 & $\ldots$ \\
$\mathbf{3}$ & -3 & -4 & -1 & +1 & +2 \\
$\mathbf{4}$ & -21 & +5 & +0 & +6 & +1 \\
$\mathbf{5}$ & $\ldots$ & +13 & $\ldots$ & +15 & +3 \\
\hline
\end{tabular}

\section{Regression Results}

In what follows, the impact of these possible determinants of regional divergence--inherited industrial structure and regional fiscal policies - is analyzed econometrically by relating their indicators to income mobility of regions between 1991 
and $1997 .^{23}$ The six-year transition matrix covering this period is shown in Appendix II, with the cells filled in with the corresponding regions. ${ }^{24}$ In order to capture the pattern of income mobility between 1991 and 1997, two categorical variables were constructed:

INCMOB3 and INCMOB5. Each region was assigned a rating corresponding to its income change over the period, and these ratings were compiled to create the two variables. INCMOB3 divides all regional income movements during this period into three groups (downward, level, and upward) and hence captures the direction of mobility. INCMOB5 comprises five groups and hence reflects also the size of income movements by separating out larger leaps (of more than one income state). The resulting structure of the two variables is as follows:

INCMOB3

$-1-$ moved down to a lower income state ( 42 percent of regions),

0 - remained in the same income state ( 30 percent of regions),

1 - moved up to a higher income state ( 28 percent of regions).

\section{INCMOB5}

-2 - moved down by more than 1 income state ( 8 percent of regions),

-1 - moved down by 1 income state (34 percent of regions),

0 - remained in the same income state (30 percent of regions),

1 - moved up by 1 income state ( 21 percent of regions),

2 - moved up by more than 1 income state ( 7 percent of regions).

${ }^{23}$ Of course, other economic conditions and policies may have also contributed to the increase in interregional income inequality. Specifically, it would be instructive to examine the impact of differences in the pace and scope of structural reforms implemented in the regions on their economic performance. However, for the lack of comprehensive structural reform indicators at the regional level, this issue remains a subject for future research.

${ }^{24}$ It appears that most of the traditionally poor regions and those that suffered as a result of transition are located in the western and southern parts of the country, while the traditionally wealthy regions and those that gained from transition are located in the northern and eastern parts, although there are exceptions. It is interesting that the observed pattern of income mobility seems to be at odds with the direction of interregional migration. Heleniak (1997) shows that while in the 1970s and 1980s the direction was from the western and southern parts to the North, Siberia, and the Far East, during the 1990s it was reversed and the northern and eastern areas recorded net population outflows. This suggests that interregional migration in Russia has been driven more by social and environmental factors (such as ethnic tensions and severe climates), than by economic motives. Furthermore, even though some restrictions on population mobility have been relaxed, migration remains limited by the internal passport control system and insufficient availability of housing. 
Further, dummy variables were used to control for the initial income position of each region as of 1991 . Divergence dynamics of the kind identified in the transition matrix analysis above could affect the direction and the size of income changes for regions starting at different income levels. In addition, regions starting in the extreme income state 1 (5) face zero probability of moving down (up), which could influence their income mobility patterns. Likewise, regions starting in states 2 (4) cannot move by more than one income state down (up). Thus, the dummies were set up as follows (with D3 chosen as the omitted dummy):
D1 - income state 1 ( 7 percent of regions),
$\mathrm{D} 2$ - income state 2 (24 percent of regions),
D3 - income state 3 (50 percent of regions),
D4 - income state 4 (11 percent of regions),
D5 - income state 5 ( 8 percent of regions).

In order to assess the role of possible determinants of regional income mobility, an ordered logit estimation was used, with INCMOB3 and INCMOB5 regressed on a number of explanatory variables, along with the initial income dummies. This estimation is, effectively, a transition matrix analogue of a standard growth regression: the growth variable is categorical, rather than continuous, and the initial income variable is split into a set of dichotomous variables, in accordance with the state structure of the matrix. The following variables reflecting inherited industrial structure and regional fiscal policies were used as explanatory variables in the regressions:

EXTRACT: share of extracting industries in regional industrial output, 1995 PROCESS: share of processing industries in regional industrial output, 1995 NE: share of national economy expenditure in total expenditure, 1992

DNE: change in share of national economy expenditure in total expenditure, 1992-1997

For the most part, these variables describe economic conditions faced by traditional enterprises across regions. Indeed, they have little relation to private sector activity, as reflected by the proportion of new firms created since the onset of reforms in 1992. ${ }^{25}$ Since private sector development is an essential component of transition and is widely recognized as the engine of sustainable growth, it is important to control for differences in this parameter across regions. The following variable was used for this purpose:

NEWENT: number of enterprises created over 1992-1997, relative to all enterprises

${ }^{25}$ The simple cross-regional correlation of the proportion of new firms created over $1992-97$ is 0.10 with the share of extracting industries, -0.17 with the share of processing industries, -0.05 with the share of national economy expenditure, and -0.04 with the change in this latter share over the period. 
The results of the ordered logit estimation are presented in Table 6 . The coefficients on the dummy variables reflect mostly the extreme state constraints, with polarization tendencies masked further by the exclusion of the middle income state. Income mobility is positively related to the share of extracting industries, while the effect of the share of processing industries is negative, though statistically insignificant. The initial share of national economy expenditure and its change over the period are both positively and significantly related to income mobility. Regional performance appears to be determined primarily by traditional enterprises, with no significant impact of newly created private firms. Together, these findings offer support to the idea that the more successful regions derived their success not from the market-oriented economic reorganization, but rather from favorable external environment and continued public injections in traditional enterprises. Over the period from 1991 to 1997 , regions were more likely to move up the income ladder and less likely to move down if they happened to be rich in natural resources and if they maintained and further increased budgetary subsidies. Income dynamics during this period were largely unrelated to the development of the new private sector, casting doubts on the actual progress of market-oriented reforms across regions. These findings point to the need for more active reforms not only in the weaker, but also in the stronger regions, in order to promote development of a viable private sector that can serve as an engine of sustainable growth over the long term.

Table 6. Determinants of Regional Income Mobility: Ordered Logit Estimation

\begin{tabular}{|l|ll|ll|}
\hline & \multicolumn{2}{|c|}{ INCMOB3 } & \multicolumn{2}{c|}{ NCMOB5 } \\
\hline EXTRACT & $0.02(0.01)^{*}$ & $0.03(0.01)^{* *}$ & $0.03(0.01) * * *$ & $0.03(0.01) * * *$ \\
PROCESS & $-0.03(0.02)$ & $-0.02(0.02)$ & $-0.02(0.02)$ & $-0.02(0.02)$ \\
NE & $0.10(0.05) * *$ & $0.10(0.05)^{* *}$ & $0.10(0.05) * * *$ & $0.10(0.05) * * *$ \\
DNE & $0.07(0.04) * *$ & $0.08(0.04)^{* * *}$ & $0.08(0.03) * * *$ & $0.08(0.03) * * *$ \\
NEWENT & & $0.04(0.03) *$ & & $0.02(0.03)$ \\
\hline D1 & $2.77(1.07) * * *$ & $2.47(1.08)^{* * *}$ & $2.93(0.98) * * *$ & $2.77(1.02) * * *$ \\
D2 & $1.00(0.61) * *$ & $1.18(0.64) * *$ & $1.15(0.58) * * *$ & $1.21(0.58) * * *$ \\
D4 & $-0.24(0.88)$ & $-0.30(0.87)$ & $-0.78(0.87)$ & $-0.80(0.87)$ \\
D5 & $-1.50(0.95) *$ & $-1.74(0.99) * *$ & $-2.08(0.99)^{* * *}$ & $-2.13(0.99)^{* * *}$ \\
\hline N & 74 & 74 & 74 & 74 \\
pseudo-R2 & 0.11 & 0.12 & 0.11 & 0.11 \\
\hline
\end{tabular}

*** significant at 5 percent, ${ }^{* *}$ significant at 10 percent, * significant at 15 percent standard errors in parentheses

\section{Conclusion}

This paper analyzed the dynamic pattern of comparative regional development during transition in Russia, using the transition matrix methodology. In sharp contrast to pretransition times, it revealed that regional income mobility over the period from 1991 to 1997 tended toward a highly uneven long-term distribution with the majority of regions at relatively low income levels and a minority of higher income regions. A 
comparison of the initial phase of the transition process to the more advanced phase suggests that the tendency for regional divergence was to some extent reversed after 1995 , but the tendency for the majority of regions to be trapped at lower income levels remained. However, statistical evidence of a structural break between the two phases turned out to be weak.

The observed income mobility pattern was related to a number of variables reflecting the industrial structure and fiscal policies of Russian regions, using ordered logit estimation. The findings suggest that over the period from 1991 to 1997 the more successful regions prospered largely on account of their natural resource endowments and favorable external environment, while continuing to resist efficiency-enhancing reorganization by supporting traditional enterprises. The less successful regions were trapped at relatively low income levels due to uncompetitive industries and lack of resources needed for restructuring. Income dynamics during this period were largely unrelated to the development of the new private sector, but were instead determined by operations of traditional enterprises present in the regions prior to transition. Therefore, the answer to the question posed in the title of this paper appears to be "procrastination", calling for more decisive reforms in the regions in order to create a sound foundation for sustainable economic growth. 
I. Transition Evolution of the Regional Income Distribution

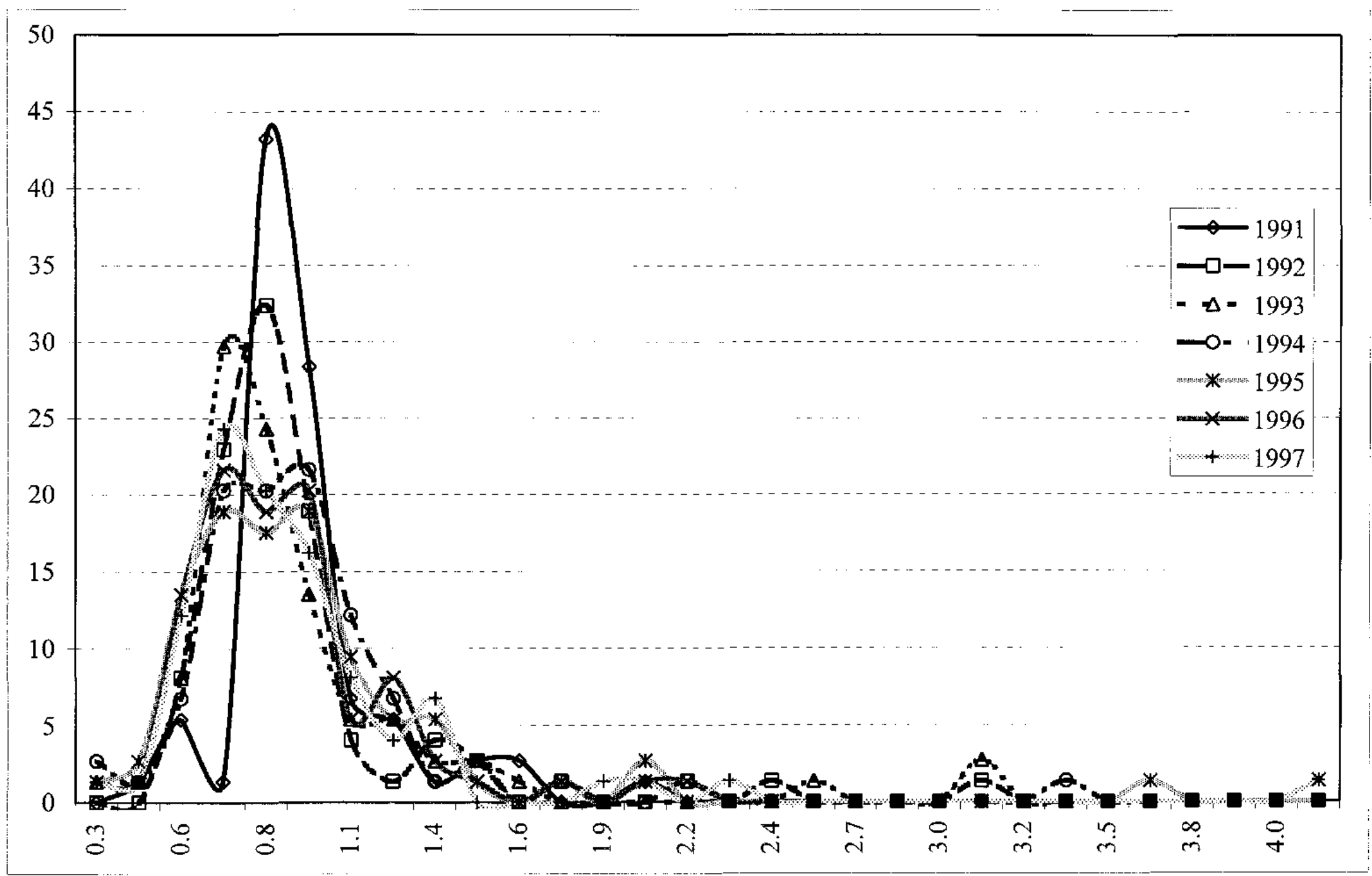




\section{Regional Income Mobility from 1991 (Rows) to 1997 (Columns)}

\begin{tabular}{|c|c|c|c|c|c|}
\hline & 1 (poor) & 2 (lower middle) & 3 (middle) & 4 (upper middle) & 5 (rich) \\
\hline 1 (poor) & $\begin{array}{l}\text { Adygeya rep., Dagestan } \\
\text { rep. }\end{array}$ & $\begin{array}{l}\text { Karachaevo-Cherkessia rep., Gorniy } \\
\text { Altay rep. }\end{array}$ & Khakassiya rep. & & \\
\hline $\begin{array}{l}2 \text { (lower } \\
\text { middle) }\end{array}$ & $\begin{array}{l}\text { Chitinskaya obl., Tuva } \\
\text { rep., Penzenskaya obl., } \\
\text { Mari-El rep., Northern } \\
\text { Osetia rep., Kabardino- } \\
\text { Balkaria rep., Kurskaya } \\
\text { obl., Mordovia rep. }\end{array}$ & $\begin{array}{l}\text { Tambovskaya obl., Kirovskaya obl., } \\
\text { Chuvashia rep. }\end{array}$ & $\begin{array}{l}\text { Smolenskaya obl., Tatarstan rep., } \\
\text { Leningradskaya obl., Tverskaya } \\
\text { obl., Kostromskaya obl., } \\
\text { Bashkortostan rep. }\end{array}$ & Permskaya obl. & \\
\hline $\begin{array}{c}3 \\
\text { (middle) }\end{array}$ & $\begin{array}{l}\text { Kurganskaya obl., } \\
\text { Vladimirskaya obl., } \\
\text { Stavropolskiy krai }\end{array}$ & $\begin{array}{l}\text { Orenburgskaya obl., Kaluzhskaya obl., } \\
\text { Ivanovskaya obl., Altayskiy krai, } \\
\text { Ulyanovskaya obl., Omskaya obl., } \\
\text { Yaroslavskaya obl., Nizhegorodskaya } \\
\text { obl., Voronezhskaya obl., } \\
\text { Volgogradskaya obl., Astrakhanskaya } \\
\text { obl., Ryazanskaya obl., Kaliningradskaya } \\
\text { obl., Bryanskaya obl. }\end{array}$ & $\begin{array}{l}\text { Arkhangelskaya obl., } \\
\text { Belgorodskaya obl., Krasnodarskiy } \\
\text { krai, Rostovskaya obl., } \\
\text { Novgorodskaya obl., Amurskaya } \\
\text { obl., Tulskaya obl., Saratovskaya } \\
\text { obl., Udmurtia rep., Orlovskaya } \\
\text { obl., Lipetskaya obl., } \\
\text { Novosibirskaya obl. }\end{array}$ & $\begin{array}{l}\text { Pskovskaya obl., } \\
\text { Buryatia rep., } \\
\text { Samarskaya obl., } \\
\text { Chelybinskaya obl., } \\
\text { Irkutskaya obl. }\end{array}$ & $\begin{array}{l}\text { Sverdlovskaya obl., } \\
\text { Moskovskaya obl., } \\
\text { Vologodskaya obl. }\end{array}$ \\
\hline $\begin{array}{l}\text { (upper } \\
\text { middle) }\end{array}$ & Kalmykia rep. & Primorskiy krai & Khabarovskiy krai, Karelia rep. & Kemerovskaya obl. & $\begin{array}{l}\text { Krasnoyarskiy krai, } \\
\text { Tomskaya obl., } \\
\text { Komi rep. }\end{array}$ \\
\hline 5 (rich) & & Sakhalinskaya obl. & & Murmanskaya obl. & $\begin{array}{l}\text { Kamchatskaya obl., } \\
\text { Tyumenskaya obl., } \\
\text { Sakha (Yakutia) rep., } \\
\text { Magadanskaya obl. }\end{array}$ \\
\hline
\end{tabular}




\section{REFERENCES}

Atkinson, A.B., and J. Micklewright, 1992, Economic Transformation in Eastern Europe and the Distribution of Income" (Cambridge: Cambridge University Press).

Aghion, P., and S. Commander, 1999, "On the Dynamics of Inequality in the Transition," Economics of Transition, Vol. 7 (2), pp. 275-98.

Banerjee, A.V., and E. Duflo, 2000, "Inequality and Growth: What Can the Data Say?" NBER Working Paper No. 7793 (Cambridge, Massachusetts: National Bureau of Economic Research).

Barro, R.J., 2000, "Inequality and Growth in a Panel of Countries," Journal of Economic Growth, Vol. 5 (1), pp. 5-32.

Becker, C.M., and D.D. Hemley, 1996, "Interregional Inequality in Russia During the Transition Period," Comparative Economic Studies, Vol. 38 (Spring), pp. 55-81.

Commander, S., and U. Lee, 1998, "How Does Public Policy Affect the Income Distribution: Evidence from Russia 1992-1996" (Unpublished; London: European Bank for Reconstruction and Development).

Commander, S., A. Tolstopiatenko, and R. Yemtsov, 1999, "Channels of Redistributions," Economics of Transition, Vol. 7 (2), pp. 411-47.

Freinkman, L.M., and P. Yossifov, 1999, "Decentralization in Regional Fiscal Systems in Russia: Trends and Links to Economic Performance" (Washington: World Bank).

Freinkman, L.M., D. Treisman, and S. Titov, 1999, "Subnational Budgeting in Russia: Preempting A Potential Crisis," World Bank Technical Paper No. 452 (Washington: World Bank).

Freinkman, L.M., and M. Haney, 1997, "What Affects the Propensity to Subsidize: Determinants of Budget Subsidies and Transfers Financed by the Russian Regional Governments in 1992-1995," World Bank Policy Research Working Paper No. 1818 (Washington: World Bank).

Garner, T.I., and K. Terrell, 1998, “A Gini Decomposition Analysis of Inequality in the Czech and Slovak Republics During the Transition," Economics of Transition, Vol. 6 (1), pp. $23-46$.

Goskomstat (various statistical yearbooks).

Hanson, P., and M. Bradshaw, eds., 2000, Regional Economic Change in Russia (Northampton, Massachusetts: E. Elgar). 
Heleniak, T., 1997, "Internal Migration in Russia During the Economic Transition," Post-Soviet Geography and Economics, Vol. 38 (February), pp. 81-104.

Keane, M.P., and E. Prasad, 2000, "Inequality, Transfers and Growth: New Evidence from the Economic Transition in Poland," IMF Working Paper 00/117 (Washington: International Monetary Fund).

Kremer, M., A. Onatski, and J.H. Stock, 2001, "Searching for Prosperity," NBER Working Paper No. 8250 (Cambridge, Massachusetts: National Bureau of Economic Research).

Lavrov, A., and others, 1996, "Analiz tendentsii razvitia regionov Rossii v 1992-1995 godah," Voprosi Economiki, Vol. 6, pp. 42-77.

Milanovic, B., 1999, "Explaining the Increase in Inequality During the Transition," Economics of Transition, Vol. 7 (2), pp. 299-341.

Quah, D.T., 1993, "Empirical Cross-Section Dynamics in Economic Growth," European Economic Review, Vol. 37 (April), pp. 426-34.

Quah, D.T., 1997, "Empirics for Growth and Distribution: Stratification, Polarization and Convergence Clubs," Journal of Economic Growth, Vol. 2, pp. 27-59.

Shleifer, A., and D. Treisman, 2000, "Without A Map: Political Tactics and Economic Reform in Russia" (Cambridge, Massachusetts: MIT Press).

Shorrocks, A., 1976, "Income Mobility and the Markov Assumption," Economic Journal, Vol. 86, pp. 566-78.

Smith, A., 1996, "From Convergence to Fragmentation: Uneven Regional Development, Industrial Restructuring, and the 'Transition to Capitalism' in Slovakia," Environment and Planning, Vol. 28, pp. 135-56.

Stokey, N.L., and R.E. Lucas, and E.C. Prescott, 1989, Recursive Methods in Economic Dynamics (Cambridge, Massachusetts: Harvard University Press). 